EGU2020-18953

https://doi.org/10.5194/egusphere-egu2020-18953

EGU General Assembly 2020

(c) Author(s) 2020. This work is distributed under

the Creative Commons Attribution 4.0 License.

\title{
Assessment of buildings exposure and potential losses to landslides based on census data
}

\author{
Sérgio C. Oliveira ${ }^{1}$, Raquel Melo ${ }^{1}$, Carlos Alves ${ }^{2}$, Jorge Rocha ${ }^{1}$, Ricardo A. C. Garcia ${ }^{1}$, Alexandre \\ Tavares $^{3}$, José L. Zêzere ${ }^{1}$, Susana Pereira ${ }^{1}$, Pedro P. Santos ${ }^{1}$, Paulo Morgado ${ }^{1}$, and Nuno Costa ${ }^{1}$ \\ ${ }^{1}$ Centre for Geographical Studies, Institute of Geography and Spatial Planning, Universidade de Lisboa, Edifício IGOT, Rua \\ Branca Edmée Marques, 1600-276 Lisbon, Portugal (cruzdeoliveira@campus.ul.pt) \\ ${ }^{2}$ Institute of Geography and Spatial Planning, Universidade de Lisboa, Lisbon, Portugal \\ ${ }^{3}$ Centre for Social Studies and Earth Sciences Department, Universidade de Coimbra, Colégio de S. Jerónimo, Largo D. Dinis, \\ 3000-995 Coimbra, Portugal
}

Landslides, like any natural hazardous process, do not generate risk until some type of interaction with human settlements or activities occur. Consequently, the landslide susceptibility assessment and the quantification of the exposure and potential losses of structures and infrastructures is crucial for informing emergency and spatial planning in areas prone to geomorphological hazards. Thus, the major aim of this work is to identify the current and future buildings' exposure to landslides, in order to get useful information to support decision planners.

The current spatial distribution of buildings and future exposure trends will be assessed based on the Portuguese Census data, which will be used as ancillary information to derive the number and type of buildings at the basic census polygonal unit. The future buildings' exposure will be determined from a cellular automata simulation model.

Four types of buildings are considered: E1 - light structures of wood or metal; E2 - buildings of adobe, rammed earth or loose stone walls; E3 - buildings with brick or stone masonry walls; and E4 - buildings of masonry walls confined with reinforced concrete. The evaluation of buildings' exposure is made for two landslide event scenarios: one for shallow soil slips (with rupture surfaces depth $<1.5 \mathrm{~m}$ ) and another one for deep-seated slides (with rupture surfaces depth $>1.5$ $\mathrm{m})$. The landslide susceptibility/hazard hotspots for both scenarios are assessed in a study area corresponding to four municipalities located in the northern sector of the Lisbon Metropolitan Area, Portugal. The landslide susceptibility models are based on a bivariate statistical method (Information Value) and on a dataset of eight independent variables assumed as predisposing factors for the occurrence of landslides: lithology, slope, curvature, aspect, slope/contribution area ratio, topographic position index (TPI), soil type and land use. The validation procedures include the computation of ROC curves and the calculation of AUROC. Landslide susceptibility and buildings' exposure are presented as probabilities at the basic census unit scale. Results combine the probability of occurrence of a landslide with the probability of having a building of a certain type potentially affected by a landslide, for the two landslide event scenarios. 
Finally, potential losses on buildings are assessed from exposure and damage on buildings caused by landslides in the past.

Acknowledgements:

This work was financed by national funds through FCT-Portuguese Foundation for Science and Technology, I.P., under the framework of the project BeSafeSlide-Landslide Early Warning soft technology prototype to improve community resilience and adaptation to environmental change (PTDC/GES-AMB/30052/2017) and by the Research Unit UIDB/00295/2020. Pedro Pinto Santos is funded by FCT through the project with the reference CEEIND/00268/2017. 